This item was submitted to Loughborough's Research Repository by the author.

Items in Figshare are protected by copyright, with all rights reserved, unless otherwise indicated.

\title{
An holistic approach to understanding the changing nature of organisational structure
}

PLEASE CITE THE PUBLISHED VERSION

http://dx.doi.org/10.1108/09593841011052138

PUBLISHER

(C) Emerald Group Publishing Limited

VERSION

AM (Accepted Manuscript)

LICENCE

CC BY-NC-ND 4.0

REPOSITORY RECORD

Doherty, Neil, Donna Champion, and Leitao Wang. 2019. "An Holistic Approach to Understanding the Changing Nature of Organisational Structure”. figshare. https://hdl.handle.net/2134/13418. 
This item was submitted to Loughborough's Institutional Repository (https://dspace.lboro.ac.uk/) by the author and is made available under the following Creative Commons Licence conditions.

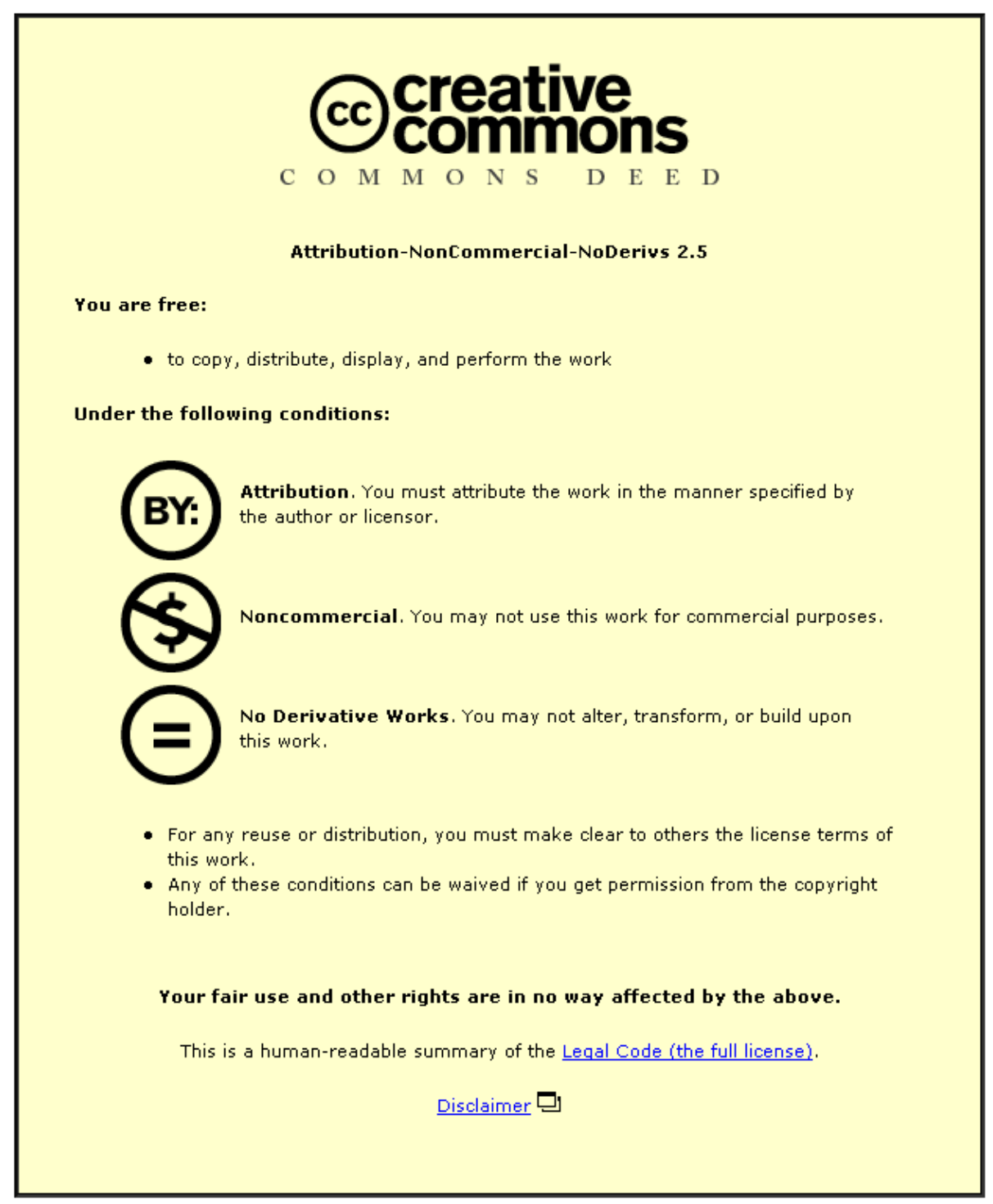

For the full text of this licence, please go to: http://creativecommons.org/licenses/by-nc-nd/2.5/ 


\title{
An holistic approach to understanding the changing nature of organisational structure
}

\author{
Prof Neil F. Doherty, Dr Donna Champion, Dr Leitao Wang \\ The Business School, \\ Loughborough University, \\ Loughborough, \\ Leicestershire LE11 3TU, UK.
}

TEL: +44 (0) 1509 223128; Email: n.f.doherty@lboro.ac.uk

Key Words: Enterprise Resource Planning; Corporate Strategy; Organizational Structure; Chinese Manufacturing sector.

\begin{abstract}
Purpose of this paper

The purpose of the exploratory study, reported in this paper, was to revisit and critically reappraise the impact of IT upon organizational structure, by exploring how the deployment of ERP, when accompanied by a specific strategic orientation, impacted upon the host organisation's structural design.

Design/methodologylapproach

The study was initially enacted through a postal questionnaire survey of IT managers within a sample of China's largest manufacturing organisations. Follow-up interviews were then conducted with senior managers, who had first-hand experience of working on ERP implementations, to help us more fully understand the impact of ERP upon organisational structure.
\end{abstract}

\section{Findings}

The study found that the implementation of ERP technology and the strategic orientation of the host organisation are both likely to modify the structural design of Chinese manufacturing organisations. Moreover, it has been found the success of an ERP deployment is a stronger predictor of organizational form, than the scale of the deployment. The results of the study would also suggest that ERP is more likely to affect structural changes, when deployed in the presence of a complementary 'Prospector' corporate strategy.

\section{Practical implications}

This study provides clear new evidence that ERP is likely to have a significant impact upon organisational structure, but, because of the complexity of the technology and the uniqueness of every organisational context, we offer no simple prescriptions or panaceas, as to how it should be managed. However, managers should be aware that an ERP implementation will almost certainly affect organisational structure, and then take steps to ensure that such changes are carefully and proactively managed.

\section{What is original/value of paper}

There is already a rich and established literature with regard the impact of IT upon organisational structure. However, we would argue that by focussing upon ERP, by explicitly modelling the effect of strategy and by taking a holistic view of organizational structure, we have been able to offer a far more subtle view of the complexities of the relationship between IT and organizational structure, than prior studies.

Paper type: research 


\section{Introduction}

Because of its critical role in support of the day to day operations and the strategic positioning of the modern business enterprise, information technology has become a ubiquitous and increasingly significant part of the fabric of most organizations. Consequently, the implementation of information technology within organisations almost invariably results in a wide variety of, often very significant, impacts upon the design of the business, its economic performance and the working conditions of members of staff [Markus \& Robey, 1988; Clegg et al, 1997; Doherty \& King, 1998]; technical change is the catalyst for organisational change. Information technology cannot, however, be viewed as a deterministic artefact, as it does not generally behave in a well ordered and predictable manner [Grint \& Woolgar, 1997]. Organizational stakeholders have the potential to interpret, appropriate and ultimately shape their information systems in a wide variety of ways [Orlikowski, 1992]. This view - typically termed 'social constructivism' [Bijker, 1995] - is supported by the wealth of evidence that shows how the application of identical technologies, in very similar organisational contexts, can often result in radically different organisational impacts [Orlikowski, 1993]. For example, Sahay and Robey [1996] have demonstrated how the implementation of a particular geographical information system, in two very similar governmental agencies, resulted in two very different organizational outcomes: a significant impact on working practices in one county government organization, as opposed to very limited change in another. Consequently, a significant problem facing the systems developer and the systems sponsor is that the impacts and outcomes of introducing a new information system cannot generally be predicted at the project's outset, as the system may be interpreted and appropriated in multifarious ways, during the development period, as well as throughout its operational life [Orlikowski et al, 1995].

Based upon this constructivist logic, it might appear unwise to attempt to study the incidence of organizational impacts from the application of a specific class of technology and expect any clear patterns or regularities to emerge. However, the wisdom of such a strategy may well depend upon the type of artefact under investigation, the types and significance of the impacts being sought, and the context in which the study were to be conducted. As we will argue in the following section, it was envisaged that the structural impacts of ERP systems in Chinese manufacturing companies would make a legitimate and significant target for our study because as well as addressing an under researched topic, there was also a strong likelihood that such impacts would share some commonality across similar organisations However, given the significant role that corporate strategy can also play in an organization's structural design [Galan \& Sanchez-Bueno, 2009], we also chose to explicitly include this important, yet under-researched construct. Having used the literature, in the second section, to justify and delineate our research focus, the next sections are used to review the research methods employed and present the study's findings, before critiquing their contribution and implications in the concluding section.

\section{Literature Review and Theory Development}

The aim of this section of the paper is to review the literature, and in so doing, provide a focus for the paper that would give a new and very different perspective on the much debated question of how IT might affect organisational structure. More specifically we wanted 
to re-evaluate this rich and established stream of literature, and in so doing, provide explicit answers to the following questions:

i. What dimensions of organisational structure to use for the dependent variable?

ii. What type of information technology to choose as the independent variable?

iii. Should any additional independent variables be included in the study?

iv. In what organisational context should the study be conducted?

The remainder of this section explicitly addresses each of these questions, before presenting the set of research objectives that were derived from this review, to ensure that the study would ultimately deliver important new insights into the role of IT in shaping organizational structure.

\subsection{The Dimensions of Organizational Structure}

The serious study of the organizational effect of IT implementations on organizational structure probably began in the 1950s with Leavitt and Whisler's [1958] seminal paper, which predicted that information technologies were likely to: 'change the role and scope of middle managers' and encourage 'large organisations to recentralise'. Since then, there has been a steady flow of empirical and conceptual studies that have explored the impact of a variety of types and configurations of information technology on a range of different structural characteristics [e.g. Simon, 1977; Zuboff, 1988; Cyert \& March, 1992; Klein 2001; Dibrell and Miller 2002; Sauer and Willcocks 2003]. However, despite the longevity of this stream of research, previous contributions can be criticised because of the narrow conceptualisations of organizational structure, which have been adopted when modelling the dependent variable.

In prior studies of the impact of IT upon organizational structure, the most persistent and intensive scrutiny has been applied to the potential of information technologies to modify the locus of decision making, in terms of its level of centralization [e.g. Robey, 1977; Pinsonneault and Kraemer 1993; Hitt \& Brynjolfsson, 1997]. Another reasonably common theme in the organisational literature has been the impact that new technologies might have on the standardisation and formalisation of working practices and procedures [e.g. Winjhoven \& Wassener, 1990; Dewett \& Jones, 2001; Spanos et al, 2002], although such studies have tended to address centralization, as well as standardization. By contrast, the impact of IT on other important dimensions of organisational structural - such as the span of control, the degree of horizontal integration, or the number of hierarchical layers - has been rather neglected. This partial and narrow focus of previous studies means that it is difficult to get an overall and holistic view of the impact of IT on organizational structure [Robey, 1981].

\subsection{The impact of ERP on Organisational Structure}

It is also possible to criticise the way in which the independent variable - the adoption of information and communications technologies has been represented in previous studies. For example, many early studies focused upon the amount of IT hardware in use, particularly computer terminals [Whisler, 1970; Storey, 1987], whilst others have sought to assess the overall level of investment in information technologies [Hitt \& Brynjolfsson, 1997]. Yet another 
common approach has been to try to evaluate the extent to which each, of a variety of different technologies, have been used in an organization [Spanos et al, 2002; Winjhoven \& Wassener, 1990]. Whilst all of these studies have helped to further our understanding of the impact of IT on structure, they can be criticised for their fairly naïve modelling of the IT artefact, which doesn't allow for a clear causal relationship between technology and structure to be hypothesised. Another key criticism of existing studies is that they only attempt to model the adoption of technology, rather than its successful operation. Given the unacceptably high rates of systems' rejection, failure or sub-optimal operation [e.g. Clegg et al, 1997; Doherty \& King, 2001], it would seem unlikely that that simply deploying a portfolio of technological artefacts is going to engender significant organizational impacts. However, significant structural changes may be realised once the technology has been successfully appropriated, and it is routinely delivering benefits, in areas such as enhanced information quality and improved service quality [Delone and McLean, 2003].

Against this backdrop, we wanted to conduct a study which focused upon a single, clearly defined technology, which could then be modelled, in terms of both its scale and its success, but which particular technology to focus upon. Once more, the literature was very helpful in establishing a clear candidate, namely the enterprise resource planning [ERP] package. ERP is typically acquired in the form of packaged software, with integrated modules that support all major business functions across an organisation, such as production, distribution, sales, finance and HR management [Kumar \& Van Hillegersberg 2000]. Moreover, ERP implementations are promoted on the basis that they incorporate 'best practice' [Miranda 1999], and encourage organizations to streamline and standardize their business processes across the organization and within individual business units [Nah et al. 2004].

It was envisaged that ERP technology would make an excellent focus for this study, as not only does it present a single and well defined type of software application, which is increasingly common, also the potential of ERP to engender significant organizational impacts has been widely recognised. For example, Markus et al [2004] have argued the introduction of a highly integrated ERP system, within a manufacturing company, is likely to have a significant impact on that organisation's business processes, structure, culture and enterprise level performance, as well as the motivation, job specifications and performance of individual employees. Moreover, whilst the impact of ERP on organizational structure has been widely recognised [Fahy 2001] there has, to date, been very little empirical analysis to ascertain the nature, form and circumstances of such structural impacts. A further justification for choosing to focus upon the impacts of ERP systems, for the purposes of this study is that due to their relatively low 'interpretive flexibility' [Doherty et al, 2006], there was a reasonable chance that any resultant impacts would reflect a relatively high degree of commonality, across a sample of manufacturing organisations. As Kallinikos [2004; p. 11] notes: 'contextual adaptation and re-shaping of such packages [ERP systems] cannot undo the logic and very pre-suppositions on which the package is predicated'. 


\subsection{The Impact of Strategy upon Organizational Structure}

When attempting to model the impact of a technology upon an organization's structure, it is important to recognise that other organizational characteristics might also shape structure. For example, it has been argued that organizational strategy will strongly influence an organization's structural configuration [Lynch 2000]. In particular, the configuration theories clearly suggest that organizational structure should be arranged in such a way to serve its strategy and strategic priorities [Doty et al. 1993]. However, there is a growing debate as to whether strategy shapes structure [Galan \& Sanchez-Bueno, 2009] or whether strategy follows structure [Fredrickson, 1986]. In one of the most recent contributions to this debate, Galan \& Sanchez-Bueno [2009] have found that in the long-term strategy both shapes and follows organizational structure, but that it is the shaping effects of strategy, which are the stronger. Given its important role in shaping structure, it is clear that any study of the structural impacts of IT should also take into account the potentially influential role of organizational strategy, but, in practice this approach has been adopted in precious few prior studies.

\subsection{The Uptake and Impact of ERP in Chinese Manufacturing Companies}

Many previous studies of the impact of IT on organizational structure can be criticised because they don't focus upon a clearly defined organizational context, and therefore it can be difficult to determine the extent to which variations in the impacts might be associated with differences in the company's size, operational sector or cultural context. Consequently, we wanted to focus our study upon a single size of company, operating in a single homogenous sector, within just one country. Moreover we wanted to focus upon a homogenous group of companies that had not been the subject of much previous scrutiny: to this end, we targeted large, manufacturing organizations operating in China.

Although there have been many previous studies with respect to the uptake and application of ERP within Western countries, few studies have been specifically focused on developing countries, in general, or China, in particular. Moreover, those few studies that have focused upon the uptake and application of ERP implementation in China [e.g. Huang and Palvia 2001; Westrup and Liu 2008; Newman and Zhao, 2008] have not explicitly addressed the organizational impacts. Moreover, it was envisaged that as ERP packages reflect a 'western' management philosophy [Martinsons 2004], it would be interesting to ascertain whether any of the structural impacts or alterations might be needed to adjust to this 'western' model of best practice, embedded in the package.

\subsection{Critique of Literature and Research Objectives}

As this review of the literature has demonstrated, the relationship between IT and organizational structure is a topic that has already attracted a great deal of attention from organizational researchers, as has the uptake, application and impact or ERP. However, it has still been possible to identify a number of important gaps in this body of literature, which have helped to shape the study presented in this paper. In particular, in designing this study, the multi-faceted nature of organizational structure and differing ways of measuring ERP deployment were both explicitly recognised. Moreover, the need to explicitly model the 
influential role that strategy might have on organizational structure was also recognized, as was the importance of locating the study in a developing market economy, such as China. With these themes in mind, the following four research objectives were derived:

$\mathrm{RO}_{1} \quad$ To explore the extent to which the deployment of ERP, when coupled with a particular strategic orientation, has engendered changes to the hierarchical configuration [span of control / structural layers] of Chinese manufacturing companies;

$\mathrm{RO}_{2}$ To explore the extent to which the deployment of ERP, when coupled with a particular strategic orientation, has resulted in changes to the centralization of decision-making within Chinese manufacturing companies;

$\mathrm{RO}_{3}$ To explore the extent to which the deployment of ERP, when coupled with a particular strategic orientation, has modified the extent to which Chinese manufacturing companies are standardised;

$\mathrm{RO}_{4}$ To explore the extent to which the deployment of ERP, when coupled with a particular strategic orientation, has transformed the level of horizontal integration within Chinese manufacturing companies;

It was envisaged that in tackling these objectives, an important contribution to the literature would be made by providing new insights into the ways in which technology shapes organisational behaviour.

\section{Research Methods}

Past studies addressing the organizational impacts of IT can be divided into two broad categories according to when they were undertaken, and also the methods that they employed. Most early studies employed a quantitative approach, underpinned by a positivist research philosophy, with the express purpose of generalizing from research findings to other situations. By contrast more recent studies have tended to employ qualitative research methods, based upon an interpretivist philosophy, with a view to uncovering richer insights into the 'meaning' of IT in organizations [Rose and Jones 2004]. In so doing, interpretive approaches do not explicitly seek, or indeed recognise the legitimacy of seeking replicable patterns, and consequently, they offer little in terms of generalizability.

Consequently, there has been something of a methodological dichotomy, with regard to previous studies of the impact of IT on organizational structure, with the result that most have provided rather limited and unbalanced views of these increasingly important phenomena. To avoid falling into this same trap and to take advantage of the growing recognition that quantitative and qualitative research can play complementary roles in organisational studies [Cavaye, 1996] both were employed in this particular study. Moreover, our research philosophy can best be described as 'pluralist', as it incorporated both interpretive and positivist elements, as recommended for the study of complex technologies, in organizational contexts [Mingers, 2003]. The initial questionnaire survey was executed using positivistic principles, but when analyzing the rich database of interview transcripts, we attempted to adopt more of an 'interpretive' style, as our overarching aim was to gain 'knowledge of reality' through the study of social constructions [Klein \& Myers, 1999]. The aim of this section is to 
firstly review how a questionnaire was designed, validated and executed, before describing the methods employed for the follow-up qualitative study.

\subsection{Design, Validation and Targeting of Research Instrument}

A detailed questionnaire was used to collect the data necessary to explore the research objectives presented in the previous section. The questionnaire was organized into the following four sections:

1. Background information: Respondents were asked to provide some background information, about their host organization, primarily in terms of its size and the industrial sector, in which it primarily operated.

2. The Structural configuration: The purpose of this section of the questionnaire was to use a series of Likert scales, each addressing a key aspect of organizational design, to explore how the respondents perceived their organization's structure. In total twenty different item measures were used to assess organizational structure, which could be grouped into the following four critical categories: organizational configuration [flatness of structure \& wide span of control etc.]; centralization of decision-making; standardization of processes and practices and level of horizontal integration.

3. The Strategic Configuration: For this study, the strategy typology suggested by Miles and Snow (1978) has been adopted. Ginn (1990) argued that Miles and Snow's work could be said to be one dimensional and consequently their four distinct strategic typologies could be put sequentially onto a single continuum, with the 'Prospector' and 'Defender' strategy anchoring either end of this continuum. . In this context, 'Prospector' organisations can be characterised as those that have a large portfolio of products and are actively seeking new market opportunities, whilst 'Defender' organisations typically have a narrow product market scope, which they seek to protect aggressively.

4. The deployment of ERP: Respondents were asked whether their organisation had adopted ERP, and if they had, a series of questions assessing the scale and success of their ERP deployment, was posed. More specifically, the following two broad themes were investigated: scale of deployment [physical diffusion \& freedom of use]; success of deployment [organizational \& informational benefits].

As there are few, if any, previous survey-based, empirical studies that explicitly address the structural impacts of ERP, it was not possible to adapt specific questions and item measures from the existing literature. Consequently, once a draft questionnaire had been created, from the related literature, it was necessary to subject it to a rigorous validation process. More specifically, the draft questionnaire was initially validated through a phased pre-testing regime, to refine the questionnaire and to identify errors. In the first phase, the survey was pre-tested by suitably qualified academics and research students In the second stage, the English version questionnaire was firstly translated into Chinese and validated by 'Back translation' [Luo and Peng 1999], to avoid any distortion in meaning. The translated questionnaire was then further tested by five Chinese managers to ensure that the meaning and purpose was clear to potential respondents. The pre-tests were very useful, as they resulted in a number of significant enhancements being made to the structure of the survey and the wording of specific questions. Having refined the questionnaire, a pilot study 
exercise was also undertaken, which provided valuable insights into the likely response rate and analytical implications for the full survey.

As we were primarily seeking insights into the organisational impacts of information technology, it was recognised that the most appropriate group of individuals to target would be managers and executives who had been involved in the development, management and usage of ERP systems. Consequently, in line with the research objectives, we wanted to target the questionnaire at practicing managers from large, Chinese manufacturing companies. As it was not possible to find an existing list of large Chinese manufacturers that had already adopted ERP, two popular web search engines [Google \& Baidu] were used to identify likely candidate organisations. Ultimately, a total of 1200 questionnaires were posted to the CEOs, or the general managers, of a sample of manufacturing companies and a total of one hundred and fifty six valid responses were returned from the sample of targeted companies. Based upon these figures, it was possible to determine that the response rate of the survey was a respectable thirteen percent. It should be noted that as 32 of the responding organisations had not, at that time, fully implemented their ERP systems, these responses were excluded from the multi-variate analyses.

\subsection{Qualitative Study - Purpose and Execution.}

A series of interviews was undertaken with practicing managers, to help explain, enrich and validate the findings from the statistical analyses. The interview style chosen was a semistructured approach in order to explore issues that arose from the quantitative data and in order to leave space for respondents to expand on some issues [Bryman 2006]. The design of the interview script was influenced both by the literature, and the results of the pilot study that had already been conducted for the quantitative study. To pilot test the interview design four interviews were conducted, which resulted in a number of important modifications to the interview script. A list of potential interviewees, all of whom were conveniently located in the North of China, had been derived from the sampling frame, used for our quantitative study. Each potential interviewee was contacted, and ultimately, 26 senior managers, form 21 distinct organisations, agreed to be interviewed. As can be seen from the final list of interviewees [see appendix 1] each was a senior manager. However, to check their credentials at the start of each interview, the respondents were asked to confirm that they were in a position to be able to knowledgeably comment on their organisation's strategy and ERP implementation.

Each interview was conducted in Chinese and tape-recorded to ensure that interviewees' comments were accurately collected. Each tape recording was then fully transcribed into Chinese, before being translated into English, in readiness for analysis. The data analysis strategy commenced with a within-case analysis, in which key chunks of text from the interview transcripts were highlighted, and annotated with 'in-vivo' codes - that is codes derived from phrases used repeatedly by informants (Strauss and Corbin, 1990). Following the within case, a variable oriented cross-case analysis (Miles \& Huberman, 1994) was conducted to identify key themes and patterns across the sample. To ensure that a rich and valid interpretation of the data was achieved, the within-case and cross-case analysis was 
not conducted in a single iteration. Indeed, the researchers sought to 'understand the whole' by continually revising it in 'view of the reinterpretation of the parts' (Myers, 1994; 56). Consequently, the researchers continued to re-visit the documentary evidence and the interview responses to help integrate the individual pieces of evidence into a coherent whole (Butler, 1998).

\section{Quantitative Analysis}

The section aims to critically review the influences that the implementation of ERP, when coupled with a particular strategic orientation, may have on a range of organizational structural dimensions - configuration, centralization, standardization and interdepartmental relationships - as illustrated in Figure 1. It should be noted that these findings are based exclusively on an analysis of the quantitative data, whilst the qualitative data is presented, in the following section, to help interpret and explain the results of the statistical analysis.

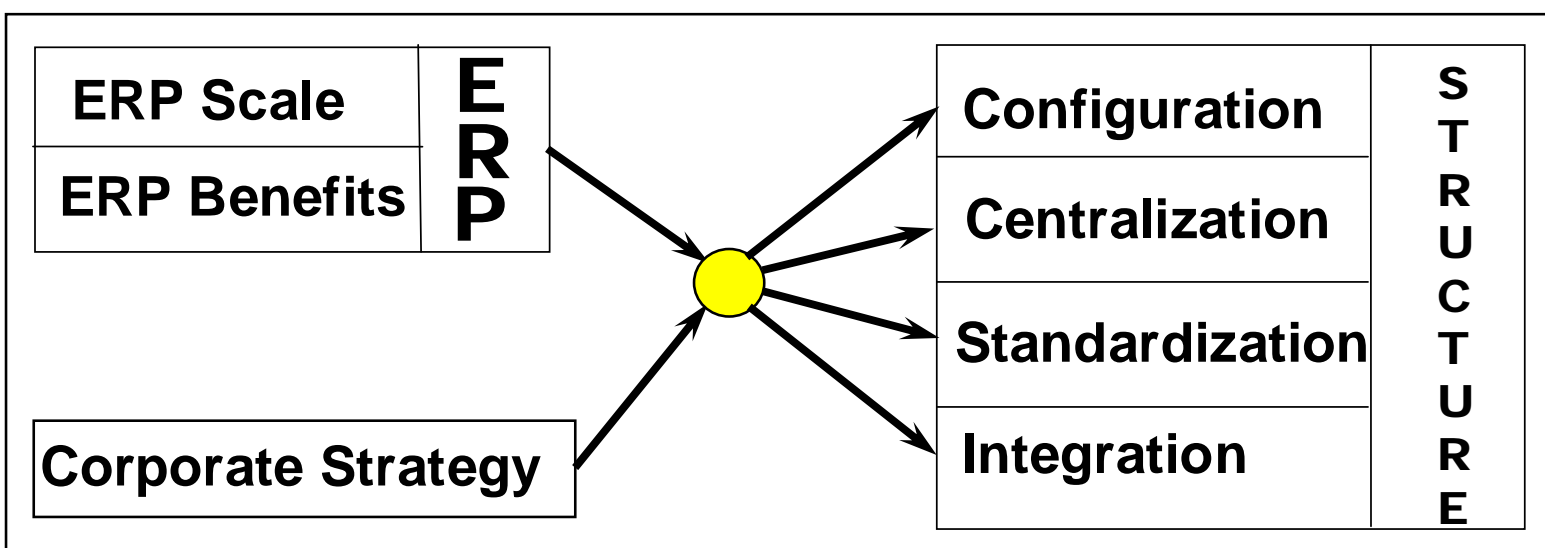

Figure 1: ERP Deployment and Organizational Structure

\subsection{Data reduction through the Identification of factors}

Given the high number of individual item measures included in the survey, a series of factor analyses were used to establish whether this data could be consolidated into a smaller number of distinct factors. Factor analysis is a means of summating information contained in a large number of variables into a smaller set of new composite factors, with a minimum loss of information [Hair et al, 1998]. To simplify interpretation, independent factor analyses were run on each of the seven variable sets, as shown in figure 1. The ratio of the number of variables to the sample size is an important prerequisite for factor analysis success. Hair et al, [1998] suggest that the minimum for an acceptable ratio is at least five observations for each variable included in the analysis. In this study, the ratios of responses to variables were all very comfortably over this threshold, with the lowest ratio being $10.4: 1$, for the 'ERP Benefits' item measures. Furthermore, it was established that the measure of sampling adequacy (MSA) scores, for each factor, as measured using the KMO \& Bartlett's test of sphericity, were all well within tolerance. Consequently, it was confirmed that factor analysis was an appropriate tool to use in these circumstances. 
Principal components factor analysis, with a varimax rotation, was the chosen method for the factor analysis, as it is easier to interpret the results Hair et al, [1998]. The application of the 'Scree' test and a review of the 'Eigen' values were used to determine the most statistically significant number of factors for each of the variable sets. Ultimately, a total of eight factors were identified from the seven variable sets, each of which was given a factor name, which was chosen to best represent the nature of its constituent items. The factor names and their characteristics have been presented in table 1 . Having successfully isolated and named eight distinct factors, it was also important to test their validity and reliability. The internal reliability of each factor was, therefore, examined using Coefficient 'alpha'. Ideally, alpha scores should exceed 0.70 , although scores of 0.60 and above are acceptable [DeVellis, 1991]. In this instance, three of the factors can be classed as 'ideal' (factors: 6-8), whilst a further three can be classed as 'acceptable' (factors: $1-3$ \& 5). Unfortunately, the Cronbach's 'alpha' value for the remaining factor (\#4) had dipped under the threshold of 0.60 , but as it was still comfortably over 0.50 , Kaiser [1974] has argued that such results are valid, when conducting 'exploratory' studies, such as this one.

Table 1: Factors created for use in the statistical analyses

\begin{tabular}{llcccc}
\hline$\#$ & Construct & Items & Mean & High value & Low value \\
\hline 1 & Hierarchical Configuration & 3 & 3.41 & Very flat structure & Very hierarchical structure \\
2 & $\begin{array}{l}\text { Centralization of Decision- } \\
\text { making }\end{array}$ & 4 & 4.67 & Highly centralised & Highly de-centralised \\
3 & Formal Standardization & 3 & 4.89 & Very standardized & Not very standardized \\
4 & Horizontal Integration & 4 & 4.82 & Very integrated structure & Very strong boundaries \\
5 & ERP coverage & 5 & 4.40 & Wide ERP coverage & Narrow ERP coverage \\
6 & ERP informational benefits & 7 & 5.34 & Significant benefits & Insignificant benefits \\
7 & ERP operational benefits & 8 & 5.07 & Significant benefits & Insignificant benefits \\
8 & Strategic Orientation & 6 & 4.98 & 'Prospector' orientation & 'Defender' orientation \\
\hline
\end{tabular}

\subsection{The relationship between the ERP Adoption / Strategic Orientation \& Organizational Structure}

The relationship between the four independent factors [ERP coverage; informational benefits; operational benefitsand strategic orientation], and the four dependent factors that measure the organizations' structural arrangement was explored using multiple regression analysis. Multiple regression analysis was deemed appropriate, as the data met the assumptions for a regression analysis and the ratio of independent variables to cases was 39:1, which comfortably exceed the threshold value of $5: 1$ [Hair et al, 1998]. A 'stepwise' regression approach was adopted, to allow the contribution of each independent variable to be assessed iteratively. As can be seen from the results of these analyses [table 2], a series of highly significant regression models could be found to help explain changes in organizational structure, as reflected in the level of centralization, standardization 
configuration and horizontal integration. The remainder of this section takes each of these structural dimensions, in turn, and explores how they might be impacted by ERP and strategy.

Table 2: Results of Multiple Regression Analyses

\begin{tabular}{|c|c|c|c|c|}
\hline $\begin{array}{l}\text { Regression } \\
\text { no }[\#]\end{array}$ & Constant $[\alpha]$ & $\begin{array}{c}\beta 1 \text { = 1st Variable } \\
\text { [coefficient] }\end{array}$ & $\begin{array}{c}\beta 2=2^{\text {nd }} \text { Variable } \\
\text { [coefficient] }\end{array}$ & $\begin{array}{c}\text { Dependent } \\
\text { Variable }\left[R^{2}\right]\end{array}$ \\
\hline 1 & 0.89 & $\begin{array}{l}\text { ERP Operational } \\
\text { benefits }[0.241]\end{array}$ & $\begin{array}{l}\text { Strategic } \\
\text { orientation [0.232] }\end{array}$ & $\begin{array}{c}\text { Configuration } \\
{[0.142]^{\star * *}}\end{array}$ \\
\hline 2 & 5.84 & $\begin{array}{l}\text { ERP Operational } \\
\text { Benefits [-0.232] }\end{array}$ & & $\begin{array}{c}\text { Centralization } \\
{[0.055]^{*}}\end{array}$ \\
\hline 3 & 1.53 & $\begin{array}{l}\text { ERP Informational } \\
\text { benefits [.430] }\end{array}$ & $\begin{array}{l}\text { Strategic } \\
\text { orientation [0.240] }\end{array}$ & $\begin{array}{c}\text { Standardization } \\
{[0.215]^{\star \star *}}\end{array}$ \\
\hline 4 & 0.54 & $\begin{array}{l}\text { ERP Coverage } \\
{[0.787]}\end{array}$ & & $\begin{array}{c}\text { Integration } \\
{[0.781]^{\star \star *}}\end{array}$ \\
\hline
\end{tabular}

*** significant at the .001 level; ${ }^{* *}$ significant at the .01 level; * significant at the .05 level.

\section{The impact of ERP / Strategy upon Configuration}

One effect of ERP adoption might be that it helps managers increase their span of control through more efficient and effective information provision and better communication, and in so doing facilitates a flattening of organizational structures [Avgerou 2000]. Alternatively, if ERP is viewed as a mechanism for downsizing, but the structure is not modified, then the span of control may be reduced. A third possibility is that the hierarchical configuration is primarily a function of the organization's strategy, which the implementation ERP simply reinforces.

To explore these potential relationships between ERP, strategy \& hierarchical configuration, a step-wise linear regression was conducted to better under the most significant influences. The results of this analysis [see table 2: equation 1] suggest that both the organization's strategic orientation and the success of the ERP implementation, in terms of the realization of operational benefits, have a significant affect upon the degree to which the organization's structure can be categorized as either flat or hierarchical. More specifically, the results suggest that as an ERP implementation starts to deliver meaningful operational benefits, then the need for a steep chain of command is reduced, and the organizational structure can be flattened. A plausible interpretation of this result might be that a successful ERP implementation can facilitate improvements in process efficiency and customer responsiveness [Chand et al, 2005; Velcu, 2007], which can help organizations to more effectively manage its workforce, and thereby flatten the organizational hierarchy by removing redundant layers of management. What seems clear from these results, is that successful ERP adoption allows its powerful information processing and communications capability [Kumar and Van Hillegersberg 2000] to be realized, which allows managers to make decisions, monitor staff, and communicate decisions more efficiently and effectively [Pinsonneault and Kraemer 1993]. 
Whilst the successful adoption of ERP is shown to have the most significant impact upon the configuration of organizational structure, it can also be seen from the results, presented in table 2, that strategic orientation also appears to influence configuration. More specifically, the more closely an organization's strategy conforms to the 'Prospector' archetype, the more likely it will be that it flattens its structure. This result supports Miles and Snow's [1978] hypothesis that 'Prospector' organizations will typically avoid the traditional, multi-layered, bureaucratic structures, which are prone to 'information distortion' [Fincham and Rhodes 1999], in favour of flatter structures, which help them to respond positively to emerging problems and opportunities. A final interesting observation from the quantitative analysis is that the scale of an ERP implementation, in terms of its breadth of coverage, doesn't appear to have any impact upon organisational configuration. Simply implementing a large-scale ERP system will not be sufficient to flatten structures. It appears that efforts to flatten structures and reduce the span of control will only begin once an implementation is operating successfully, and delivering meaningful benefits, particularly when this is coupled with a 'Prospector' orientation.

\section{The impact of ERP / Strategy upon Centralization}

This subsection aims to explore the combined influence of ERP adoption and strategic orientation on the degree of organizational centralization. On the one hand, it can be hypothesized that the scale and success of an ERP implementation should be positively associated with the degree of organizational decentralization: the dissemination of information to employee workstations, across the enterprise, should facilitate employee empowerment [Psoinos et al, 2000]. An alternative, yet equally plausible, hypothesis is that ERP adoption will facilitate the centralization of decision-masking [Torkzadeh \& Doll, 1999]. Equally, it could be that an organization's decision-making stance is primarily dependent upon its strategic orientation, and that ERP simply plays a secondary role in this respect.

As illustrated by Table 2 [equation 2], a significant negative association has been found between 'ERP operational benefits' and the resultant level of 'organizational centralization'. More specifically, the negative association between 'operational benefits' and 'organizational centralization' suggests that as the system becomes more successfully embedded within the organization, then the more likely it will be that it starts to decentralize its decision-making processes. One plausible interpretation of this result is that once the daily operation of the organization can be easily dealt with by virtue of successful ERP implementation, lower level staff can also make decisions, an activity they did not enjoy before the adoption of ERP. In the case of the centralization construct, neither the organization's strategic orientation, nor the scope of its ERP implementation were found to have any significant relationship with this important dimension of organizational structure.

\section{The impact of ERP / Strategy upon Standardization}

Although there has been a paucity of field studies exploring how ERP will influence organizational standardization, it might be reasonable to hypothesize that ERP adoption will result in a more standardized organizational structure. This is because ERP is a process- 
oriented technology, designed to integrate the whole organization together [Davenport 2000]. Thus, organizations will need to standardize their working practices in order to satisfy the requirements of an ERP implementation [Hall 2002].

In terms of the nature of the relationship between ERP and standardization, the results of the multiple regression [Refer to Table 2; equation 3] suggests that there are significant associations, between the realization of 'informational benefits' and the resultant degree of standardization'. One plausible interpretation of this result is that once an ERP implementation is delivering high quality information and enabling organizational activities to be more effectively monitored, then the more likely it will be that it can standardize its working practices and business processes, across the organization. As with the configuration and centralization constructs, the scale of the ERP implementation was not found to have any significant association with the degree of standardization.

The positive association between the standardization of working practices and the adoption of a Prospector-oriented strategy, is perhaps more surprising and therefore worthy of comment. Miles \& Snow [1978] originally postulated that as 'Prospector' organisations needed to be more responsive to market conditions, they would therefore need to adopt more flexible, and less standardized, working practices. However, as Prospector organizations are also typically flatter and less centralized [Miles \& Snow, 1978], it can be argued that they need to adopt more standardized processes and practices, to enable flexibility, whilst avoiding fragmentation [Child \& McGrath, 2001].

\section{The impact of ERP / Strategy upon Horizontal Integration}

It has often been argued that as ERP has a strong process-orientation, its implementation is likely to play an important role to play in facilitating higher levels of horizontal integration, within the business enterprise [Davenport, 2000; Oakland \& Porter, 2000]. However, in their study of the influence of ERP upon team working, Koch and Buhl [2001] found that team working, across departments, was not reinforced though ERP adoption. Against this backdrop we were keen to revisit this relationship, in the context of ERP adoption amongst Chinese manufacturing companies. The results of the multiple regression analysis [see table 2: equation 4] suggest, that in the case of horizontal integration, it is wide-scale deployment of ERP, rather than its success or the host organisation's strategic orientation that are most likely to engender improvements in the level of horizontal integration. This result is perhaps not surprising as the mechanisms for inter-departmental integration are typically hard-wired into the ERP software, and will therefore be activated as soon as the technology has been widely deployed.

\section{Results of Qualitative Survey}

The results from the multi-variate analysis of the questionnaire data suggest that both strategic orientation and the successful adoption of ERP have a significant impact upon organizational design. However, these findings provide no real insights as to whether such impacts were an explicit part of the host organisation's ERP plan, or whether they were perceived to have occurred by happenstance. Moreover, it is not possible to determine from 
the results of the quantitative analysis whether successful ERP adoption was perceived to have been the catalyst for organizational change, or whether it simply helped to reinforce pre-existing strategies. These two questions were addressed through a series of qualitative interviews with a sample of senior organisational mangers, all of whom had experience of ERP implementations, the results of which are reported upon in the remainder of this section.

It has previously been suggested that the primary drivers for the adoption of ERP are internally-oriented technological and business imperatives [Markus and Tanis, 2000], such as the need to replace aging legacy systems, a requirement for increased system capacity, the need for customer-oriented information or the desire for higher levels of process-integration. The results of this analysis suggest that, in China, the stimuli for ERP adoption are both external and internal, in terms of their orientation. For example, in 6 out of the 20 companies, in which interviews were conducted, it was reported that ERP was implemented in response to a directive from their head office, or from a controlling government ministry. For example, as the Finance Director of one state-owned enterprise [C13] noted:

'...the decision was taken by our supervisory government ministry, as before our company was listed on the stock exchange, the government had promised our external investors that our company would do this. The ministry wanted to deliver a clear message to our external investors that we will standardize our company and offer them more transparent information'.

In another organization, the HR Director [C6] noted that the decision to adopt ERP had been taken in response to a request from a powerful customer, whilst the IT Manager [C19] of a state-owned enterprise noted that:

'...ERP was implemented to send a message to the market-place that we would operate in a way they would understand".

In the remaining organisations, the justification for ERP adoption had been more internally oriented, most commonly to cope with expansion, to improve process design and integration or to provide better information. Indeed, in many organisations, interviewees did acknowledge that structural changes, most commonly in the areas of enhancements to standardisation and integration, were explicit drivers for ERP implementation. As one IT Director [C10] noted: 'our first priority was to integrate the whole company's businesses and processes, that is, to solve some historic problems'. He went on to note that his organisation wanted to standardise its processes and practices around western models of management, and in so doing, 'eliminate the influence of traditional Chinese management practices'. Consequently, we found a mixed situation in which an explicit desire to modify organisational structure was often perceived to have been one of many drivers for ERP adoption, but not by any means the dominant driver.

When it comes to whether or not ERP and strategy were perceived to have had a direct impact upon organizational structure, it became apparent that the nature of the relationship was dependent upon the type of structural change, under consideration. For example, there was a fairly strong consensus that successful deployment of ERP had facilitated improvements in the level of horizontal integration and the degree of process standardization. For example, with regard to standardisation, one interviewee noted [C15]: 
'ERP makes clear the entire department's responsibility and all departments have quite clear procedures to do the job. ERP formalizes those responsibilities and procedures so that all staff do their job and duties according to the ERP system in order to guarantee normal running. If they don't, then management can easily locate the problematic link.'

Indeed, the majority of interviewees acknowledged that the standardization of working practices had been both an express aim of the ERP implementation, and something that had been witnessed in practice, once the system was operational. With regard to integration there was a very clear consensus that ERP had helped to integrate business processes and working practices, across functions, and in so doing, it had greatly improved interdepartmental communications. As the CEO of one organisation [C3] noted, before the introduction of ERP everyone concentrated on their own job, without worrying about how this might impact upon any of the downstream processes.

By contrast, there was far less evidence that ERP implementation had engendered any changes to the host organisation's configuration. In only three organisations [C8, C9 \& C10] was ERP believed to have directly facilitated a reduction in the number of hierarchical levels, primarily through its ability to deliver improvements in efficiency and routinisation. In the majority of organizations, interviewees either argued that ERP implementation did not have any impact upon organisational configuration, or that their ERP implementations had been tailored to suit their existing hierarchical arrangements. For example, in six of the participating organisations, it was noted that corporate structures had been flattened in recent years, but the managers who were interviewed regarded this process to have been primarily as a result of strategy, rather than ERP adoption. As one director [C12] noted the company had flattened its structure in the late 1990s, and that this change had been strategy led: he noted that ERP adoption had helped to reinforce and embed this strategy within the company.

Modifications to the degree to which decision-making is centralised / decentralised is the final, and perhaps most interesting area, in which the impacts of ERP were explored, as the results of the quantitative study had presented a rather mixed picture. In a slim majority of organisations [11/21], the interviewees felt that the adoption of ERP had not had any discernable impact upon the centralization of decision-making. Indeed, these interviewees suggested that the style of decision-making is primarily dependent upon leadership style and strategy, rather than ERP adoption. This view was reflected strongly by one manager [C3] who insisted that there had been no change to decision making as: '... a strict hierarchy is necessary for staff to be strictly controlled'. By contrast, five of the interviewees from five organisations felt that their organisations had been able to decentralise their decision-making processes, because ERP was able to provide junior managers with more timely and accurate information. In the remaining organisations, interviewees perceived that ERP had reinforced centralisation, in some areas, but facilitated empowerment elsewhere. In addition to commenting on the degree to which ERP had engendered more or less centralisation, a number of interviewees also noted that some decision rights had been 'absorbed into' [C6], 'prescribed by' [C14] or 'been transferred from managers to' [C1] the ERP software. Indeed, 
one interviewee [C4] went as far as suggesting that 'ERP helps to reduce the level of human discretion'.

A common theme voiced, across our sample of interviewees, was that although a successful ERP implementation could modify organisational structures, it might take many months before these changes became apparent. For example, one IT Director [C8] explained that initially ERP had no immediate effect on staffing levels, but once it had been operating for a number of months they had been able to significantly reduce the number of managerial levels, and the headcount, particularly within the accounting area. He went on to predict that 'with such significant improvements in operational efficiency, it is inevitable that there will be further reductions in management levels'. However, he acknowledged that this was likely to 'take some time; you can't expect management levels to be reduced immediately after the adoption of ERP".

\section{Discussion and Concluding Remarks}

This research revisits and critically reappraises an important and much debated topic namely the impact of IT on organizational structure. In so doing, an important contribution has been made by explicitly addressing many of the deficiencies of prior works: this study adopted a richer and more holistic model of structure; focused upon ERP, a well defined technology with a low interpretive flexibility, and targeted a well bounded and underresearched research context [large, Chinese manufacturing companies]. Moreover, by explicitly recognising that corporate strategy is also likely to have a significant impact upon an organization's structure, we have attempted to provide a more complete account of the organizational impact of IT. In so doing, we have been able to offer a more subtle and richer view of the complexities of the relationship between ERP and organizational structure; different dimensions of structure are related with different characteristics of ERP and different strategic orientations. For example, the results of the quantitative analyses suggest that the configuration of an organization is influenced by ERP benefits and strategic orientation, but not by the ERP scale. Similarly, organizational standardization is also influenced by both ERP benefits and strategic orientation. By contrast, the degree of centralization is primarily influenced by the operational benefits of ERP, but not by its scale or the host organization's strategic orientation. Finally, horizontal integration is strongly affected by the scope of an ERP implementation, whilst ERP benefits and strategic orientation have no discernable impact upon the level of integration.

Given that the quantitative study has provided important, rather than resounding, evidence that ERP deployment is likely to have a wide ranging impact on organisational structure, the follow-up interviews were seen as an important mechanism to help confirm and further interpret the results of the statistical analyses. In brief, the analysis of the twenty-six substantive interview scripts indicated that the successful deployment of ERP was, indeed, felt to have resulted in more standardized working practices, more distributed decisionmaking and a higher degree of horizontal integration. However, the interviewees were generally less convinced that ERP deployment has facilitated changes in organisational configuration; as it was generally reported that any changes to the hierarchical arrangements 
were more likely to have been influenced by strategy than through the deployment of ERP. By reviewing the quantitative and qualitative results in their entirety, what seems clear is that when a large-scale and successful ERP system is deployed in an organisation with a Prospector orientation, then there is a strong likelihood that the organisation will become flatter, the decision-making will be less centralised, the level of horizontal integration will increase and its working practices will become more standardized. However, the interview results suggest that this broad generalization is likely to unfold in a multitude of ways, depending upon the nature and priorities of the host organisation. As many previous studies [Elbanna, 2008; Gregor et al, 2007; Palamino et al, 2007] have found, an ERP implementation is an extremely complex and problematic undertaking, and consequently, it is likely that every organisation will witness its own unique set of organisational impacts.

The relationship between the success of an ERP implementation and the re-shaping of organisational form is a further area in which this study makes an important contribution to the literature. Most prior studies into the impact of IT upon organizational structure have assumed that it is simply the scale and the functionality of the technology roll-out that will ultimately determine the extent to which organisational structures are reconfigured [Cyert \& March, 1992; Klein 2001; Dibrell and Miller 2002]. However, in finding that it is the success of an ERP deployment that plays the dominant role in reshaping corporate structure, we have uncovered an interesting new result, to which there are two plausible interpretations. The first interpretation is that ERP systems will only deliver benefits in circumstances in which the host organisation's structure is already well aligned, with the structural models and assumptions that are embedded within the ERP system [Morton \& Hu, 2008]. The competing hypothesis is that management teams will only be prepared to make any significant changes to their organisations' structure, to better align it with ERP, once the ERP implementation has proved its worth, and started to deliver important benefits. Although our research doesn't prove any conclusive answers to this debate, the interview results do tend to suggest that by and large it is successful ERP adoption that is driving structural change.

Although we have sought to adopt systematic and rigorous research approaches, there is only so much ground that a single study can cover. In particular, we would have liked to have been able to probe the role of strategic orientation a little more fully, as we have highlighted its importance, but didn't have the opportunity to fully explore its interactions with ERP and structure, when conducting the interviews. Consequently, there are important opportunities for follow-up studies, which are explicitly designed to build upon and extend our reported findings. Of particular interest, will be detailed longitudinal studies of organizations that are adopting ERP, so that its structural impacts can be studied over an extended period. In so doing, a more complete picture of the impact of information technologies upon organisational structure may start to emerge.

\section{References}

Avgerou, C. [2000] "IT and organizational change : an institutionalist perspective", Information Technology and People, 13 (4). pp. 234-262.

Bijker, W. E. [1995] Of Bicycles, Bakelites \& Bulbs, MIT Press: Cambridge.

Bryman, A. [2006] "Integrating Quantitative and Qualitative Research: How is It Done." Qualitative Research 6 [1], pp 97-113.

Butler T [1998] Towards a hermeneutic method for interpretive research in information systems. Journal of Information Technology 13, 285-300. 
Cavaye, A.L.M.. [1996] Case Study Research: A Multi-Faceted Research Approach for IS, Information Systems Journal, 6, 3, 227-242.

Chand, D., Hachey, G., Hunton, J., Owhoso, V., \& Vasudevan, S. [2005] "A balanced scorecard based framework for assessing the strategic impacts of ERP systems", Computers in Industry, $\mathbf{5 6}$ pp.558-72.

Child, J. \& McGrath, R.G. [2001] "Organizations unfettered: Organizational form in an informationintensive economy", Academy of Management Journal 44 [6], pp. 1135-1148.

Clegg, C. W., Axtell, C., Damadoran, L., Farbey, B., Hull, R., Lloyd-Jones, R., Nicholls, J. Sell, R. \& Tomlinson, C. [1997] "Information Technology: a study of performance and the role of human and organizational factors", Ergonomics, 40 [9], pp. 851-871.

Cyert, R.M. and March, J.G. [1992] A Behavioural Theory of the Firm. Cambridge, Mass., Oxford: Blackwell.

Davenport, T. H. [2000] Mission Critical: Realizing the Promise of Enterprise Systems. Boston, Mass., Harvard Business School Press.

DeLone, W.D. and McLean, E.R. [2003] "The DeLone and McLean model of information systems success: a ten year update" Journal of Management Information systems 19 [4] pp 9-30.

Dewett, T. and Jones, G.R. [2001] "The role of information technology in the organization: a review, model, and assessment", Journal of Management 27 [3], pp. 313-346.

Dibrell, C.C. and Miller, T.R. [2002] "Organizational design: the continuing influence of information technology", Management Decision 40 [6] pp 620-627.

Doherty, N.F. and King, M., [1998] "The Importance of Organisational Issues in Systems Development", Information Technology \& People, 11 [2] pp 104-123.

Doherty, N.F. \& King, M. [2001] "An investigation of the factors affecting the successful treatment of organizational issues in systems development projects". European Journal of Information Systems, 10, pp 147-160.

Doherty, N.F., Coombs, C.R. and Loan Clarke, J., [2006] "A Re-Conceptualisation of the Interpretive Flexibility of Information Technologies: Redressing the Balance between the Social and the Technical", European Journal of Information Systems, 15, pp 569-582.

Doty, D. H., W. H. Glick, et al. [1993] "Fit, equifinality, and organizational effectiveness: a test of two configurational theories" Academy of Management Journal 36 [6] pp 1196-1250.

Elbanna, A. [2008] "Implementing an Integrated System in a Socially Dis-Integrated Enterprise: A Critical View of ERP Enabled Integration", Information Technology \& People, 20 [2] pp 121139.

Fahy, M. [2001]. Enterprise Resource Planning Systems: Leveraging the Benefits for Business. London: CIMA.

Fredrickson, J. W. [1986]. "The Strategic Decision Process and Organizational Structure." Academy of Management Review 11 [2] pp 280-297.

Galan, J.I. and Sanchez-Bueno M.J. [2009] "The continuing validity of the strategy-structure nexus: new findings 1993-2003" Strategic Management Journal 30 pp1234-1243.

Ginn, G.O. [1990] "Strategic adaptation in the hospital industry: an examination of the response of the acute care hospital to the turbulent environment of the 1980s" Health Service Research 26 [4] pp 565-91.

Gregor, S., Hart, D. \& Martin, N. [2007] "Enterprise Architectures: enablers of business strategy and IS I IT alignment in government", Information Technology \& People, 20 [2], pp. 96-120.

Grint, K. \& Woolgar, S. [1997] The Machine at Work, Polity Press: Cambridge.

Hair, J.F., Anderson, R.E., Tatham, R.L., Black, W.C. [1998] Multivariate Data Analysis, Prentice Hall.

Hall, R. [2002] "Enterprise Resource Planning Systems and Organizational Change: Transforming Work Organization?" Strategic Change 11, pp 263-270.

Hitt, L. M. and E. Brynjolfsson [1997] "Information Technology and Internal Firm Organization: An Exploratory Analysis." Journal of Management Information Systems 14 [2], pp 81-101.

Huang, Z. and P. Palvia [2001] ERP Implementation Issues in Advanced and Developing Countries." Business Process Management, 7 [3] pp 276-284.

Kaiser, H.F. [1974] "Analysis of Factorial simplicity" Psychometrika 39 pp31-36.

Kallinikos, J. [2004] "Deconstructing Information Packages: Organizational and Behavioural Implications of ERP Systems" Information Technology \& People 17 [1], pp 8-30.

Klein, E.E. [2001] "Using information technology to eliminate layers of bureaucracy", The National Public Accountant 46 [4] pp 46-49.

Klein, H.K. and Myers, M.D. [1999] "A set of principles for conducting and evaluating interpretive field studies in information systems", MIS Quarterly, 23 [1] pp. 67-94. 
Koch, C. and H. Buhl [2001] "ERP-Supported Team-working in Danish Manufacturing?", New Technology, Work and Employment 16 [3], pp 164-177.

Kumar, K. and Van Hillegersberg, J. [2000] "Enterprise resource planning: introduction" Communications of the ACM 43 [4] pp. 22-26.

Leavitt, H. J. and T. L. Whisler [1958]. "Management in the 1980s." Harvard Business Review 36, [6], pp 41-48.

Luo, X. and M. W. Peng [1999]. "Learning to compete in a transition ecconomy: Experience, environment, and performance." Journal of International Business Studies 30 [2], pp 269.

Lynch, R. [2000]. Corporate Strategy, Prentice Hall.

Markus M. L. \& Robey D. [1988] The Organisational Validity of Management Information Systems. Human Relations. 36 [3], pp. 203-226.

Markus M. L. Axline, S., Petrie, D., Tanis, C. [2004] "Techno-change management: using IT to drive organizational change", Journal of Information Technology, 19 [10], pp. 4-20.

Martinsons, M. G. [2004]. "ERP in China: One Package, Two Profiles" Communications of ACM 47 [7], 65-68.

Miles, M.B. and Huberman, A.M. [1994] Qualitative data analysis. $\left(2^{\text {nd }}\right.$ Ed $)$ Thousan Oaks, CA: Sage.

Miles, R.E. and Snow, C.C. [1978] Organizational strategy, structure and process. New York: McGraw-Hill.

Mingers, J. [2003]."The Paucity of Multimethod Research: A Review of the Information Systems Literature." Information Systems Journal 13, pp 233-149.

Miranda, R. [1999] "The Rise of ERP Technology in the Public Sector." Government Finance Review 15 [4] pp 9-17.

Morton, N. A., \& Hu, Q. [2008], "Implications of the fit between organizational structure and ERP: a sdtructural contingency perspective", International Journal of Information Management, 28, pp. 391-402.

Myers, M.D. [1994] "A disaster for everyone to see: an interpretive analysis of a failed IS project," Accounting, Management and Information Technologies 4 [4] pp. 185-201.

Nah, F. F. Tan, X, \& Beethe, M. [2005] "End Users' Acceptance of Enterprise Resource Planning (ERP) Systems: An Investigation Using Grounded Theory Approach", Americas Conference on Information Systems (AMCIS), Omaha, NE, USA, pp. $2053-2057$

Newman, M. and Zhao, Y. [2008] "The process of enterprise resource planning implementation and business process re-engineering: tales from two Chinese small and medium sized enterprises" Information Systems Journal 18 pp 405-426.

Oakland, J. and Porter, S. [2000] Total Quality Management: Text and Cases. Oxford: ButterworthHeinemann.

Orlikowski, W. J. [1992] "The Duality of Technology: Rethinking the concept of technology in organizations", Organization Science, 3 [2], $398-427$.

Orlikowski, W. J. [1993] "CASE Toolsas Organizational Change: Investigating incremental and radical changes in systems development", MIS Quarterly, 17, 309-340.

Orlikowski, W.J., Yates, J. Okamura, K. \& Fujimoto, M. [1995] "Shaping electronic communication the meta-structuring of technology, in the context of use", Organization Science, 6 [4], pp 423444.

Palomino Murcia, M.A. and Whitley, E.A. [2007] "The effects of national culture on ERP implementation: a study of Colombia and Switzerland" Enterprise Information Systems 1 [3] pp. 301-325.

Pinsonneault, A. and K. L. Kraemer [1993]. "The Impact of Information Technology on Middle Managers." MIS Quarterly 17 [3], pp 271-292.

Psoinos A, Smithson S and Kern T (2000) An Exploratory study of information systems in support of employee empowerment: Constraints and opportunities. Journal of Information Technology 15, 211-230.

Robey, D. [1977]. "Computers and Management Structure: Some Empirical Findings Re-examined." Human Relations 30, pp 963-976.

Robey, D. [1981]. "Computer Information Systems and Organization Structure." Communications of the ACM 24 [10], pp 679-687.

Rose J and Jones M [2004] The Double Dance of Agency: a socio-theoretic account of how machines and humans interact. in Action in Language, Organisations and Information Systems, Goldkuhl, M., Lind, M. and Cronholm, S. (eds), Linkoping University, Sweden. 
Sahay, S. \& Robey, D. [1996] "Organizational Context, Social Interpretation, and the Implementation and Consequences of Geographic Information Systems", Accounting, Management \& Information Technology, 6 [4], 255-282.

Sauer, C. and Willcocks, L. [2003]. "Establishing the business of the future: the role of organizational architecture and information technologies." European Management Journal 21 [4] pp 497-508.

Simon, H. A. [1977]. The New Science of Management Decision. Englewood Cliffs, New Jersey: Prentice Hall.

Spanos, Y. E., G. P. Prastacos, et al. [2002] "The Relationship between Information and Communication Technologies Adoption and Management." Information and Management 39 [8], pp 659-675.

Storey, J. [1987]. "The management of new office technology: choice, control and social structure in the insurance industry." Journal of Management Studies 24 [1] pp 43-63.

Strauss, A. and Corbin, J. [1990] Basics of qualitative research: grounded theory procedures and techniques. London: Sage.

Torkzadeh G and Doll WJ [1999] The development of a tool for measuring the perceived impact of IT on work. Omega, pp 327-339.

Velcu, O. [2007]. "Exploring the effects of ERP systems on organizational performance", Industrial Management \& Data Systems, 107 [9], pp 1316-1334.

Westrup, C. and Liu, W. [2008] "Both global and local: ICTs and joint ventures in China", Information Systems Journal 18, pp. 427-443.

Whisler, T. L. [1970]. The impact of computers on organizations. New York; London: Praeger.

Wijnhoven, A. B. J. M. and D. A. Wassenaar [1990]. "Impact of information Technology on Organizations: The State of the Art." International Journal of Information Management 10 [1], pp 35-53.

Zuboff, S. [1988] In the age of the smart machine: the future of work and power. New York: Basic Books. 
Appendix 1: Summary of Interviewees Role and Company

\begin{tabular}{|c|c|c|}
\hline Company Code & Interviewee Roles & Type of Company \\
\hline C1 & $\begin{array}{l}\text { Vice President } \\
\text { IT Manager }\end{array}$ & State Owned Enterprise \\
\hline $\mathrm{C} 2$ & Marketing Director & State Owned Enterprise \\
\hline C3 & $\begin{array}{l}\text { Chairman } \\
\text { CEO }\end{array}$ & Private Venture \\
\hline C4 & Technical Director & State Owned Enterprise \\
\hline $\mathrm{C} 5$ & IT Manager & State Owned Enterprise \\
\hline C6 & HR Director & Private Venture \\
\hline $\mathrm{C7}$ & Finance Director & Private Venture \\
\hline $\mathrm{C} 8$ & IT Director & State Owned Enterprise \\
\hline $\mathrm{C9}$ & IT Director & State Owned Enterprise \\
\hline C10 & IT Director & State Owned Enterprise \\
\hline C11 & Vice Director & State Owned Enterprise \\
\hline C12 & Director of Purchasing & Foreign Owned Enterprise \\
\hline C13 & Finance Director & State Owned Enterprise \\
\hline C14 & IT Manager & State Owned Enterprise \\
\hline C15 & Purchasing Manager & Foreign Owned Enterprise \\
\hline C16 & IT Director & Private Venture \\
\hline C17 & $\begin{array}{l}\text { IT Director } \\
\text { ERP Consultant }\end{array}$ & Foreign Owned Enterprise \\
\hline C18 & $\begin{array}{l}\text { IT Manager } \\
\text { General Manager }\end{array}$ & Private Venture \\
\hline C19 & IT Manager & Private venture \\
\hline C20 & $\begin{array}{l}\text { Vice Director } \\
\text { IT Manager }\end{array}$ & Private Venture \\
\hline $\mathrm{C} 21$ & IT Director & Private Venture \\
\hline
\end{tabular}

